\title{
Workplace Violence and its Associated Factors among Nurses
}

\author{
Manisha Pandey, ${ }^{1}$ Tulsi Ram Bhandari, ${ }^{1}$ Ganesh Dangal ${ }^{2}$ \\ ${ }^{1}$ School of Health and Allied Sciences, Faculty of Health Sciences, Pokhara University, Pokhara, Nepal, \\ 2Journal of Nepal Health Research Council, Ramshahpath, Kathmandu, Nepal.
}

\section{ABSTRACT}

Background: Workplace violence among nurses is prevalent worldwide. If nurses become aware of the workplace violence and its risk factors then only they can protect themselves. This study assessed the prevalence of workplace violence and its associated factors among nurses in Pokhara, Nepal.

Methods: A hospital-based descriptive cross-sectional study was conducted in Pokhara. The required sample size of the study was 200 nurses. We adopted self-administered questionnaire developed by International Labor Office, International Council of Nurses, World Health Organization (WHO), and Public Services International. Out of 21 hospitals of Pokhara, we selected five hospitals using simple random sampling method. The number of nurses in each hospital was fixed proportionately considering the total number of employed nurses. Individual nurses were selected on the first meet first basis to gain the required number.

Results: Two-thirds (64.5\%) nurses experienced some type of violence in the last six months at their workplace. The proportion of verbal violence was higher (61.5\%) compared to the physical (15.5\%) and sexual violence (9\%). Most perpetrators of the violence were the relatives of patients and hospital employees. Age of nurses and working stations had statistically significant association with workplace violence ( $\mathrm{p}$-value $<0.05)$.

Conclusions: Workplace violence among nurses is a noteworthy problem in Pokhara whereas nearly two-thirds of nurses faced some type of violence in last six months. It is an urge to widen awareness level of nurses on the violence thus, they can take precaution themselves and ask hospital administration and other stakeholders to address the workplace violence. Keywords: Nurses, physical violence, sexual violence, workplace violence, verbal violence

\section{INTRODUCTION}

Violence is any aggressive behavior aimed at inflicting harm on other people. ${ }^{1,2}$ Workplace violence (WPV) is defined as an incident whereas staff members are abused and threatened in their work. ${ }^{3}$ Most nurses experienced some type of violence in developing as well as developed countries. ${ }^{4,5}$ Workplace violence is regarded as being a problematic and significant issue for the nursing profession worldwide..$^{6-8}$

Studies showed that nurses are three times more likely to experience violence than any other professional group. ${ }^{9}$ International Council of Nurses (ICN) claimed that globally more than two-thirds nurses did not feel safe at the workplace in 2004. Nearly $22 \%$ of nurses experienced frequent violence with patients and their relatives in European countries as well. ${ }^{10}$ It varied from place to place ranged from 10 to 95 percent in many countries worldwide. ${ }^{3,7,11-15}$ Thus this study aimed to assess the prevalence of workplace violence and its associated factors among nurses in Pokhara, Nepal.

\section{METHODS}

We conducted an institution-based cross-sectional descriptive study for assessing the prevalence and factors associated with workplace violence among nurses in Pokhara, Kaski, Nepal from July to December 2016. We calculated sample size considering $87.2 \%$ prevalence of workplace violence among nurses, ${ }^{16} 95 \%$ desired level of confidence and 5\% acceptable margin of error. The required sample size was 192; however, we rounded this figure and decided to interview 200 nurses from different hospitals. Amongst 21 hospitals of Pokhara SubMetropolitan, we selected five hospitals using simple random sampling technique. The numbers of nurses from each hospital were fixed using proportionate sampling technique and the individual nurse was selected on the
DOI: http://dx.doi. org/10.3126/jnhrc. $\mathrm{v} 15 \mathrm{i} 3.18847$
Correspondence: Tulsi Ram Bhandari, School of Health and Allied Sciences, Faculty of Health Sciences, Pokhara University, Pokhara, Nepal. Email: tulsib2004@gmail.com, Phone: +9779851240961 . 
first meet first basis.

We collected data using the self-administrative questionnaire which was developed and validated by World Health Organization (WHO), International Council of Nurses (ICN), International Labor Office (ILO) and PSI in 2003. Ethical clearance was obtained from the Institutional Review Committee (IRC) of Pokhara University. We also requested each hospital administration and obtained written permission prior to conduct studies. We took a written consent from each respondent before participation. We distributed a selfadministered questionnaire and requested for filling it in the presence of enumerator. The questionnaire includes personal and workplace-related information, prevalence of violence incidents viz. physical, verbal and sexual violence with the characteristics of respective violence. The English version of the questionnaire was translated into Nepali language and the translated version was pretested in a hospital of Pokhara Sub-metropolitan which was not included in this study. We finalized the translated version of the questionnaire with minor modification considering the results of the pretest.

We reviewed, coded and entered all collected data in Epi-data 3.1 version and transferred to SPSS 20.0 version for further analysis. First, we performed the descriptive analysis the prevalence of WPV, socio-demographic and occupational characteristics of nurses. We further applied Chi-square test to assess the association between WPV and related factors.

\section{RESULTS}

Most nurses faced some type of violence in their workplace. However, it varied regarding their demographic and socio-economic characteristics and workplace. There was also heterogeneity of demographic and socioeconomic characteristics and workplace condition of the respondents (Table 1-3).

\begin{tabular}{|c|c|c|}
\hline Characteristics & No. & Percent \\
\hline \multicolumn{3}{|l|}{ Age $(n=192)$} \\
\hline Less than 25 years & 114 & 59.4 \\
\hline 26 to 30 years & 45 & 23.4 \\
\hline 31 to 35 years & 13 & 6.8 \\
\hline 36 to 40 years & 8 & 4.2 \\
\hline 41 to 45 years & 9 & 4.7 \\
\hline Above 45 & 3 & 1.6 \\
\hline \multicolumn{3}{|l|}{ Caste } \\
\hline Dalits & 14 & 7 \\
\hline
\end{tabular}

\begin{tabular}{|lrr|}
\hline $\begin{array}{l}\text { Disadvantaged Janajati } \\
\text { Disadvantaged non-Dalit- } \\
\text { Terai caste }\end{array}$ & 31 & 15.5 \\
\hline $\begin{array}{l}\text { Relatively advantaged } \\
\text { Janajatis }\end{array}$ & 51 & 25.5 \\
\hline $\begin{array}{l}\text { Advantaged caste } \\
\text { Marital status }\end{array}$ & 102 & 51 \\
\hline Single & 90 & 45 \\
\hline Married & 104 & 52 \\
\hline Separated/Divorced & 1 & 0.5 \\
\hline Widow & 5 & 2.5 \\
\hline Position of respondents & & \\
\hline ANM & 28 & 14 \\
\hline Senior ANM & 11 & 5.5 \\
\hline Staff Nurse & 153 & 76.5 \\
\hline Senior Staff Nurse & 8 & 4 \\
\hline
\end{tabular}

Table 2. Socio-economic characteristics of nurses and their working place information $(n=200)$.

\begin{tabular}{|lrr|}
\hline Characteristics & No. & Percent \\
\hline Professional experience & & \\
\hline Less than 10 years & 169 & 84.5 \\
\hline $\begin{array}{l}\text { More than 10 years } \\
\text { Experience in current institution }\end{array}$ & 31 & 15.5 \\
\hline Less than 5 years & 157 & 78.5 \\
\hline $\begin{array}{l}\text { More than 5 years } \\
\text { Type of organization }\end{array}$ & 43 & 21.5 \\
\hline $\begin{array}{l}\text { Public } \\
\text { Private }\end{array}$ & 70 & 35 \\
\hline Non-Governmental & 74 & 37 \\
\hline Job status & 56 & 28 \\
\hline Permanent & & \\
\hline Temporary & 124 & 62 \\
\hline
\end{tabular}

\section{Table 3. Workplace information for Nurses}

$(n=200)$.

\begin{tabular}{|c|c|c|}
\hline Characteristics & No. & Percent \\
\hline \multicolumn{3}{|l|}{ Nature of job } \\
\hline Full time & 190 & 95 \\
\hline Part-time & 10 & 5 \\
\hline \multicolumn{3}{|l|}{ Nature of duties } \\
\hline Rotation & 195 & 97.5 \\
\hline Fix & 5 & 2.5 \\
\hline \multicolumn{3}{|c|}{ Working between $6 \mathrm{pm}$ to $7 \mathrm{am}$} \\
\hline Yes & 188 & 94 \\
\hline No & 12 & 6 \\
\hline \multicolumn{3}{|c|}{ Currently working wards } \\
\hline General surgery & 23 & 11.5 \\
\hline
\end{tabular}


Workplace Violence and its Associated Factors among Nurses

\begin{tabular}{|lrr|}
\hline Psychiatric & 5 & 2.5 \\
\hline Emergency & 22 & 11 \\
\hline Operating room & 9 & 4.5 \\
\hline Intensive care unit & 13 & 6.5 \\
\hline Specialized unit & 24 & 12 \\
\hline Maternity & 38 & 19 \\
\hline Medical & 21 & 10.5 \\
\hline Gynae & 9 & 4.5 \\
\hline NCU & 9 & 4.5 \\
\hline CCU & 7 & 3.5 \\
\hline Post-operative & 6 & 3 \\
\hline ENT & 5 & 2.5 \\
\hline Others (Cardiac, dialysis, & 9 & 4.5 \\
\hline elderly, private ward) & & \\
\hline
\end{tabular}

The majority of nurses $(64.5 \%)$ were reported some type of violence in their workplace. The prevalence of verbal violence $(61.5 \%)$ was higher than the prevalence of physical violence $(15.5 \%)$ and sexual violence (9\%) respectively (Figure1). Physical violence and verbal violence among nurses are mostly perpetrated by the relatives of patients whereas sexual violence is mostly perpetrated by the in-house employees. (Table 4)

Three-fourths (75\%) of the nurses of age group 3640 years were found to be more exposed to WPV. The separated, divorced and singled nurses were found more exposed to workplace violence than married nurses. ANMs and staff nurses were working in the similar settings and also reported being a victim of WPV in the similar ratio $(67.9 \%, 66 \%)$. Nurses working in nongovernmental hospitals (75\%) were more exposed to workplace violence than nurses at private and public hospitals. The table also presents that nurses less than 10 years of experience $(65.1 \%)$ had experienced more WPV. Part-time nurses (80\%) were more exposed to WPV. More than two-thirds (68.4\%) of temporary nurses had experienced workplace violence. Nurses having fixed duties had reported being a victim of WPV compared with the rotation duties. The majority of the nurses who worked at the time of $6 \mathrm{pm}$ to $7 \mathrm{am}$ (75\%) and in the intensive care unit $(84.6 \%)$ had experienced more WPV. Almost equal $(64.2 \%, 64.9 \%)$ of respondents had experienced verbal violence who were working in the institution which has reporting procedures for violence and institution that did not have reporting procedures. No significant association was found between the workplace violence and any of the socio-demographic and occupational factors (Table 5 and 6).

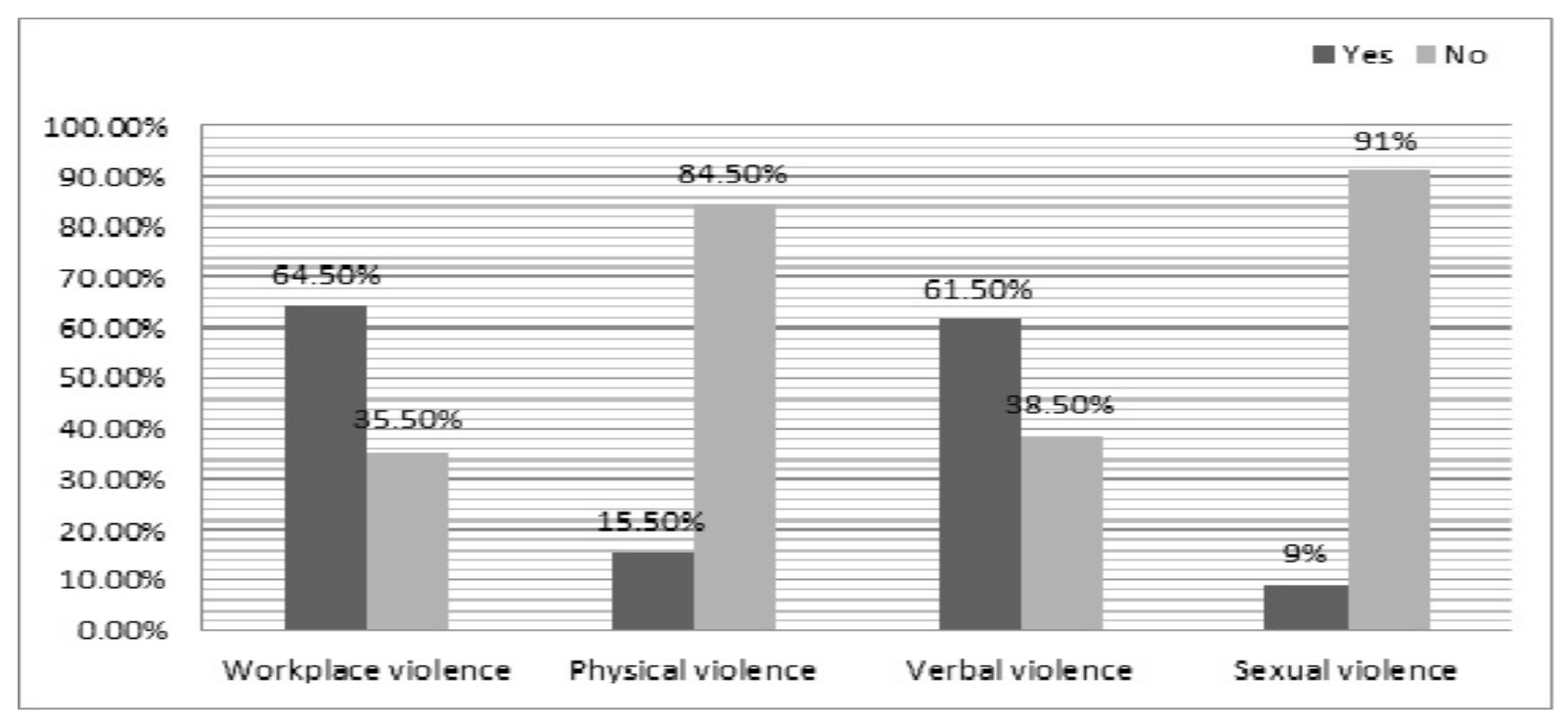

Figure 1. Prevalence of workplace violence.

Table 4. Perpetrators of workplace violence.

\begin{tabular}{lrrrrrrr}
$\begin{array}{l}\text { Types } \\
\text { violence }\end{array}$ & Patients & $\begin{array}{r}\text { Relatives of } \\
\text { patients }\end{array}$ & $\begin{array}{r}\text { Colleagues / } \\
\text { staff }\end{array}$ & Management & $\begin{array}{r}\text { External } \\
\text { worker }\end{array}$ & $\begin{array}{r}\text { In-house- } \\
\text { employees }\end{array}$ & $\begin{array}{r}\text { General } \\
\text { Public }\end{array}$ \\
\hline Physical & $29 \%$ & $41.9 \%$ & $6.5 \%$ & $15.1 \%$ & - & - & $6.5 \%$ \\
\hline Verbal & $8.9 \%$ & $51.2 \%$ & $10.6 \%$ & $2.4 \%$ & $19.5 \%$ & $7.3 \%$ & \\
\hline Sexual & $16.7 \%$ & $22.2 \%$ & $5.6 \%$ & $22.2 \%$ & $5.6 \%$ & $27.8 \%$ \\
\hline
\end{tabular}




\begin{tabular}{|c|c|c|c|c|c|c|}
\hline \multirow{3}{*}{ Characteristics } & \multicolumn{4}{|c|}{ Workplace violence } & \multirow{3}{*}{ Chi-square } & \multirow{3}{*}{$\mathrm{p}$-value } \\
\hline & \multicolumn{2}{|c|}{ Yes } & \multicolumn{2}{|c|}{ No } & & \\
\hline & No. & Percent & No. & Percent & & \\
\hline \multicolumn{7}{|l|}{ Age } \\
\hline Less than 25 years & 80 & 70.2 & 34 & 29.8 & & 0.079 \\
\hline $26-35$ years & 36 & 62.1 & 22 & 37.9 & 5.084 & \\
\hline Above 35 years & 9 & 45 & 11 & 55 & & \\
\hline \multicolumn{7}{|l|}{ Marital status } \\
\hline Single & 65 & 72.2 & 25 & 27.8 & & 0.106 \\
\hline Married & 61 & 58.7 & 43 & 41.3 & $4.482 \#$ & \\
\hline Separated/divorced/widow & 3 & 50 & 3 & 50 & & \\
\hline \multicolumn{7}{|l|}{ Position of respondent } \\
\hline ANM & 25 & 64.1 & 14 & 35.9 & \multirow{2}{*}{0.03} & 0.954 \\
\hline Staff Nurse & 104 & 64.6 & 57 & 35.4 & & \\
\hline \multicolumn{7}{|l|}{ Type of organization } \\
\hline Public & 39 & 55.7 & 31 & 44.3 & & 0.080 \\
\hline Private & 48 & 64.9 & 26 & 35.1 & 5.060 & \\
\hline Non-governmental & 42 & 75 & 14 & 25 & & \\
\hline \multicolumn{7}{|l|}{ Job status } \\
\hline Permanent & 77 & 62.1 & 47 & 37.9 & 0.823 & 0.354 \\
\hline Temporary & 52 & 68.4 & 24 & 31.6 & & \\
\hline
\end{tabular}

Table 6. Association between demographic characteristics of nurses and workplace violence.

\begin{tabular}{|c|c|c|c|c|c|c|}
\hline \multirow{3}{*}{ Characteristics } & \multicolumn{4}{|c|}{ Workplace violence } & \multirow{3}{*}{ Chi-square } & \multirow{3}{*}{$\mathrm{p}$-value } \\
\hline & \multicolumn{2}{|c|}{ Yes } & \multicolumn{2}{|c|}{ No } & & \\
\hline & No. & Percent & No. & Percent & & \\
\hline \multicolumn{7}{|l|}{ Professional experience } \\
\hline Less than 10 years & 110 & 65.1 & 59 & 34.9 & 0.165 & 0.685 \\
\hline More than 10 years & 19 & 61.3 & 12 & 38.7 & & \\
\hline \multicolumn{7}{|l|}{ Nature of job } \\
\hline Full time & 121 & 63.7 & 69 & 36.3 & $1.206 \#$ & 0.272 \\
\hline Part time & 8 & 80 & 2 & 20 & & \\
\hline \multicolumn{7}{|l|}{ Nature of duties } \\
\hline Rotational & 125 & 64.1 & 70 & 35.9 & $0.589 \#$ & 0.443 \\
\hline Fixed & 4 & 80 & 1 & 20 & & \\
\hline \multicolumn{7}{|l|}{ Work time between $6 \mathrm{pm}$ to $7 \mathrm{am}$} \\
\hline Yes & 120 & 63.8 & 68 & 36.2 & $0.648 \#$ & 0.421 \\
\hline No & 9 & 75 & 3 & 25 & & \\
\hline \multicolumn{7}{|l|}{ Currently working ward } \\
\hline $\begin{array}{l}\text { Medical/ surgical/ psychiatric/ } \\
\text { emergency/ specialized }\end{array}$ & 59 & 62.1 & 36 & 37.9 & & \\
\hline $\begin{array}{l}\text { Operating room/ post-operative/ } \\
\text { ICU/NCU/CCU }\end{array}$ & 28 & 63.6 & 16 & 36.4 & & \\
\hline Maternity/gynae. & 34 & 72.3 & 13 & 27.7 & & \\
\hline Other wards/stations & 8 & 57.1 & 6 & 42.9 & 1.845 & 0.605 \\
\hline \multicolumn{7}{|l|}{ Presence of reporting } \\
\hline Yes & 79 & 64.2 & 44 & 35.8 & 0.010 & 0.919 \\
\hline No & 50 & 64.9 & 27 & 35.1 & & \\
\hline
\end{tabular}

\# Likelihood ratio, * $\mathrm{p}$-value significant at $<0.05$ 


\section{DISCUSSION}

Nearly two-thirds nurses experienced some types of violence in the workplace in last six months. The majority of nurses $(61.5 \%)$ exposed to verbal violence in the workplace. The prevalence of physical violence and sexual violence in the workplace was reported $15.5 \%$ and $9 \%$ respectively. However, most factors such as age, marital status, position of respondents, type of organization, professional experience, nature of job, job status, nature of duties, working in night shift, working wards and presence of reporting procedure in the institution were not found significantly associated with the workplace violence viz. physical violence, verbal violence and sexual violence.

This study showed that nearly two-thirds of participants experienced workplace violence in last 6 months. This is lower than the findings of studies conducted in Palestinian hospitals $(80.4 \%)$ which had the recall period of 12 months, ${ }^{15}$ Hong Kong (76\%) with recall period of 12 months $^{8}$ and higher than the studies conducted in Northwest Ethiopia, ${ }^{17}$ Southern Ethiopia $(29.9 \%)^{18}$ and Egypt (27.7\%). ${ }^{6}$ This difference could be a lack of violence preventing strategies such as policy/procedures, training, adequate safety measures in hospitals and due to under-reporting of the violent incident.

In relation to the findings of the studies conducted in Southern Thailand, ${ }^{19}$ Palestine, ${ }^{15}$ Ghana, ${ }^{20}$ Northwest Ethiopia ${ }^{17}$ and Iran, ${ }^{21}$ this study also showed that younger and single nurses had experienced more violence in their workplace. In this study, the nurses currently working in the maternity and gynecology wards were reported mostly exposed to workplace violence. This finding is different from the study conducted in European countries which showed the higher prevalence of violence in the psychiatric, geriatric and emergency ward. ${ }^{10}$ The reason behind this difference could be that maternity and gynecology ward consists more critical patients and patients with greater pain, furthermore, the relatives of patients might have more chances to be close to the nurses in duty being possessive of their patients' condition.

This study revealed that less experienced nurses faced more workplace violence than experienced ones. Studies in Iran, Southern Thailand, and Palestine support the findings of our study. $7,10,15,21,22$ The reason behind this could be that the nurses with less experience may commit mistakes and also they may lack sound communication skills. Our study shows that staff nurses had experienced more violence than ANMs which is paradoxical with the findings of a study conducted in Iran and Jordan, which showed that nurses with lower position were exposed to workplace violence. ${ }^{7,23}$ The difference in findings might be due to variation in age and working experience between nurses and ANMs. Unlike with this study results, a study conducted in Southern Thailand ${ }^{19}$ showed that nurses working in rotating shifts experienced more violence than nurses in fixed shifts. However, in Southern Ethiopia ${ }^{18}$ was not significant association ( $p$-value $<0.05$ ) between the workplace violence and age, work experience, working ward and nature of duties. The reason behind this difference might be due to the nature of studies and varied in the sample size.

In this study, $15.5 \%$ respondents were found to be exposed to physical violence which was higher than the results of the study conducted in China $(5.8 \%)^{24}$, Southern Thailand (3.1\%), ${ }^{19}$ Egypt $(9.3 \%)^{6}$ and lower than the study conducted in Iran $(49.9 \%),{ }^{7}$ North of Iran (29.1\%), ${ }^{25}$ Palestine (20.8\%). ${ }^{15}$ Studies conducted in China ${ }^{22}$ and Iran $^{7}$ showed that the perpetrators of the physical violence were mostly the relatives of patients.

This study showed the higher percent of verbal violence than the physical violence and sexual violence which is consistent with the result of other studies. ${ }^{16,18,19,24-26}$ This difference may be due to cultural differences and the way in which violence is described. Similar findings were showed in Ghana. ${ }^{20}$ This study also shows that patient's relatives were the main perpetrators of the verbal abuse.

This study further illustrates that nine percent of the respondents in the study were exposed to sexual violence at the workplace. Studies in Ghana, ${ }^{20}$ Southern Ethiopia ${ }^{18}$ and China ${ }^{24}$ also revealed similar results about nurse's exposing to workplace sexual violence. A study conducted at Ghana ${ }^{20}$ shows that the perpetrators of the sexual violence were mostly the doctors followed by relatives of patients.

Despite the institution based cross-sectional study, this research only included quantitative information. Violence is a comprehensive and subjective phenomenon thus quantitative information may need the qualitative explanation for the precise assessment. Similarly, due to constraints of time, and resources, we took minimum required sample size. Results are based on the reported information by the respondents. Considering the limited size of the target population at the hospital, we followed first come first methods for recruiting the respondents at the hospital. 


\section{CONCLUSIONS}

Workplace violence among nurses is a major problem and matter of concern in health care. The verbal violence is common compared with physical abuse and sexual harassment in most hospitals. However, the prevalence of violence varied with age of the nurses, marital status, the tenure of experience, position, nature of job/ duties, working organization, working time, reporting procedures and working ward. Separated/divorced/ widow and working in rotational shifts and in night shifts nurse experienced more violence i.e. physical verbal and sexual. Working and stations/wards were significantly associated with physical violence. Nurses need to do self-reporting of the violent incidents that occur in their working environment. Violence prevention policies and strategies, safety measures, education and training and adoption of protective factors such as an adequate number of security guards, alarm systems, restricted visiting times could reduce the incidence of workplace violence among nurses in the hospital. There is a need to increase awareness of problems among nurses, health service managers, and the general public.

\section{ACKNOWLEDGEMENTS}

We thank all participants for their cooperation and support during the study.

\section{REFERENCES}

1. Felton JS. Violence prevention at the health-care site. Occupational medicine (HB). 1997;12(4):701-15. [Abstract]

2. Rajbhandari R, Subedi S, Kaphle HP. Workplace Violence against Health Workers: A Cross-Sectional Study from Baglung District, Nepal. International Journal of Health Sciences and Research (IJHSR). 2015;5(2):274-81. [피] Text]

3. Ahmad M, Al-Rimawi R, Masadeh A, Atoum M. Workplace Violence by Patients and Their Families Against Nurses: Literature Review. International Journal of Nursing and Health Science. 2015;2(4):46-55.[Full Text]

4. ILO I, WHO P. Framework Guidelines for addressing workplace violence in the health sector. Joint Program on Workplace Violence in the Health Sector International Labour Office, Geneva. 2002. [Full Text]

5. Wang S, Hayes L, O'Brien-Pallas L. A review and evaluation of workplace violence prevention programs in the health sector. Toronto: Nursing Health Services Research Unit.
2008.[Full Text]

6. Abbas MA, Fiala LA, Abdel Rahman AG, Fahim AE. Epidemiology of Workplace Violence against Nursing Staff in Ismailia Governorate, Egypt. J Egypt Public Health Assoc. $2010 ; 85: 29-43$. [pubMed]

7. Mahnaz Shoghi MS, Fateme S, Shiva H, Sedighe S, Ghazanfar M. Workplace Violence and Abuse Against Nurses in Hospitals in Iran. Asian Nursing Research 2008:184-93.[Full text]

8. Kwok R, Law Y, Li K, Ng Y, Cheung M, Fung V, et al. Prevalence of workplace violence against nurses in Hong Kong. Hong Kong Med J. 2006;12:6-9.[PubMed | Full text]

9. Kennedy M, Julie H. Nurses' experiences and understanding of workplace violence in a trauma and emergency department in South Africa. Health SA Gesondheid (Online). 2013;18(1):1-9. [Full text]

10. Estryn-Behar M, van der Heijden B, Camerino D, Fry C, Le Nezet O, Conway PM, et al. Violence risks in nursing-results from the European 'NEXT' Study. Occupational Medicine. 2008;58(2):107-14.[Full text]

11. Mehran Sohrabzadeh RM, Hamed T. Workplace Violence against Nurses: Provincial Data from Iran. International Journal of Hospital Research 2014:55-62. [ull text]

12. Farrell GA, Shafiei T, Chan SP. Patient and visitor assault on nurses and midwives: An exploratory study of employer 'protective'factors. Int J Ment Health Nurs. 2014;23(1):88-96.[PubMed | Full text]

13. Zampieron A, Galeazzo M, Turra S, Buja A. Perceived aggression towards nurses: study in two Italian health institutions. J Clin Nurs. 2010;19(15-16):2329-41 . [ubMed $\mid \underline{\text { Full text] }}$

14. Wu S, Zhu W, Li H, Lin S, Chai W, Wang X. Workplace violence and influencing factors among medical professionals in China. Am J Ind Med. 2012;55(11):10008.[PubMed $\mid$ Full text]

15. Kitaneh $M$, Hamdan $M$. Workplace violence against physicians and nurses in Palestinian public hospitals: a cross-sectional study. BMC Health Serv Res. 2012;12:469. [Pubmed $\mid$ Full text]

16. Balamurugan G. Violence towards Nurses. International journal of nursing. 2012 Jan 1;1(1). 
17. Tiruneh BT, Bifftu BB, Tumebo AA, Kelkay MM, Anlay DZ, Dachew BA. Prevalence of workplace violence in Northwest Ethiopia: a multivariate analysis. BMC Nurs. 2016;15:42.[PubMed $\mid$ Full text]

18. Fute M, Mengesha ZB, Wakgari N, Tessema GA. High prevalence of workplace violence among nurses working at public health facilities in Southern Ethiopia. BMC Nurs. 2015;14:9. [PubMed | Full text]

19. Kamchuchat C, Chongsuvivatwong V, Oncheunijit S, Yip TW, Santhong R. Workplace violence directed at nursing staff at general hospital in Southern Thailand. J Occup Health. 2008:201-7.]Pubmed $\mid$ Full text]

20. Boafo IM, Hancock P, Gringart E. Sources, incidence and effects of non-physical workplace violence against nurses in Ghana. Nurs Open. 2016;3(2):99-109. [PubMed | Full text]

21. Teymourzadeh E, Rashidian A, Arab M, Akbari-Sari A, Hakimzadeh SM. Nurses exposure to workplace violence in a large teaching hospital in Iran. Int J Health Policy Manag. 2014;3(6):301-5.[ubMed | Full text]
22. Xing K, Jiao M, Ma H, Qiao H, Hao Y, LiY, et al. Physical violence against general practitioners and nurses in Chinese Township Hospitals: A Cross-Sectional Survey. PloS ONE. 2015;10(11):e0142954.[Pubmed | Full text]

23. Ahmed A. Verbal and physical abuse against Jordanian nurses in the work environment. East Mediterr Health J. 2012;18(4):318. [PubMed $\mid$ Full text]

24. Jiao M, Ning N, Li Y, Gao L, Cui Y, Sun H, et al. Workplace violence against nurses in Chinese hospitals: a cross-sectional survey. BMJ Open. 2015;5(3):e006719. [PubMed $\mid$ Full text]

25. Khademloo M, Moonesi FS, Gholizade H. Health-care violence and abuse towards nurses in hospitals in north of Iran. Global J Health Sci. 2013;5(4):211-6.[라Med | $\underline{\text { Full }}$ text]

26. Darawad MW, Al-Hussami M, Saleh AM, Mustafa WM, Odeh H. Violence against nurses in emergency departments in Jordan: nurses' perspective. Workplace Health Saf. 2015;63(1):9-17.[PubMed | Full text] 